\title{
A CONTRIBUIÇÃO HERMENÊUTICA NA DETERMINAÇÃO DO LIMITE DA DISCRICIONARIEDADE NAS DECISÕES JUDICIAIS
}

\author{
Pablo Jiménez \\ Cassio José Alves Garcia Galvão
}

\begin{abstract}
RESUMO: Desenvolve estudo que motivam o conflito na jurisprudência moderna à luz da hermenêutica jurídica, pelos métodos exegético e analítico, verifica-se que na maioria das decisões judiciais inexiste fundamento sólido, científico ou filosófico. Discute a discricionariedade nas decisões em oposição à aplicação das normas e a insegurança jurídica. A insegurança jurídica é obstáculo à concretização de direitos e o uso dos recursos hermenêuticos são considerados condição necessária para harmonização dos métodos de resolução de conflitos no limite da discricionariedade nos casos difíceis, em face da efetivação da justiça no atual Estado Democrático de Direito.
\end{abstract}

PALAVRA-CHAVE: Hermenêutica; discricionariedade decisões; resolução conflitos.

ABSTRACT: It develops study that motivate the conflict in modern jurisprudence in the light of legal hermeneutics, by the exegetical and analytical methods, it's verified that in majority of the judicial decisions there isn`t solid, scientific or philosophical foundation. It discusses discretion in decisions as opposed to the application of standards and legal uncertainty. Legal insecurity is an obstacle to the realization of rights and the use of hermeneutical resources considered a necessary condition for harmonization methods of conflict resolution at limit of discretion in difficult cases, in view of the effectiveness of justice in the current Democratic State of Law.

\section{THE CONTRIBUTION OF HERMENEUTICS IN DETERMINING THE LIMIT OF DISCRICIONARITY IN JUDICIAL DECISIONS}

KEYWORDS: Hermeneutics; discretionary decisions; conflict resolution.

SUMÁRIO: Introdução. 1 Contribuição hermenêutica no pensamento jurídico histórico e contemporâneo. 1.1 A interpretação normativa. 2 Das regras de interpretação ou hermenêutica. 3 Interpretação e integração do Direito. 3.1 Métodos e técnicas de integração. 4 Da função social da hermenêutica. 5 Da discricionariedade nas decisões judiciais. Conclusão. Referências.

\section{INTRODUÇÃO}

A Teoria do Direito, fundamentalmente, nas últimas décadas, tem-se ocupado de questões que dizem respeito ao conceito e à estrutura do Direito, colocando-se, assim, em primeiro plano, a compreensão positivista e normativa e não a função do Direito. Ambas as perspectivas, a conceitual e a estrutural, não podemos negar, são de extrema importância para o estudante de Direito, pois por elas podemos entender o significado das relações e conflitos tutelados pelas normas jurídicas (SERRANO, 2017b).

A falta de uniformidade de harmonia nas decisões judiciais no contexto modero exige a discussão que propicie a melhor forma de desenvolver os processos de interpretação e

Rev. de Argumentação e Hermenêutica Jurídica | e-ISSN: 2526-0103| Goiânia | v. 5 | n. 1 | p. 1 - 16 | Jan/Jun. 2019 
integração do Direito à luz do pensamento jurídico contemporâneo.

No plano hermenêutico o conflito existe quando, sobre dois ou mais casos análogos ou similares, prevalecem intepretações antagônicas ou incompatíveis e orientadas choques de interesses. Nesse contexto importa saber: qual é a interpretação que propicia a justiça como conceito abstrato e primários e qual é a razão pela qual determinado assunto é interpretado de forma diferente.

Contudo, a problemática que estimula a presente pesquisa é de amplo conhecimento de juristas teóricos e práticos que se deparam com decisões diversas para conflitos análogos. Perante essa problemática, verifica-se que o direito, do ponto de vista funcional (funcionalismo jurídico) está longe de ser um instrumento de resolução de conflito dentro de determinados fins sociais, qual sejam, a justiça, a dignidade e o bem-estar.

É possível, com efeito, considerar que, conforme o art. $3^{\circ}$ da Constituição de 1988, a interpretação da norma vigente há de ser sempre orientada à concretização das finalidades do Estado, pois: "constituem objetivos fundamentais da República Federativa do Brasil: I construir uma sociedade livre, justa e solidária", promovendo o bem de todos, "sem preconceitos de origem, raça, sexo, cor, idade e quaisquer outras formas de discriminação".

Neste sentido, os recursos hermenêuticos apresentam-se como indicadores necessários à consecução desses objetivos. Observa-se que "interpretar uma lei implica desenvolver um processo onde se vinculam a razão, a sabedoria e a experiência ao conteúdo das relações jurídicas e das proposições prescritivas" (SERRANO, 2015, p. 13).

A analogia, de fato, é um método hermenêutico de interpretação e de aplicação do Direito auxilia no alargamento de conceitos e normas, estendendo um princípio contido em uma regra legal a outra hipótese não prevista. Por meio da analogia não se cria um direito novo.

A ausência de soluções análogos e harmônicas teve origem nas diversidades de teorias e de orientações jusfilosóficas, ainda vigorantes no pensamento jurídico brasileiro.

Vê-se que a escola Civil Law, de origem romano-germânica, prevaleceu no Direito brasileiro, sendo a lei fonte primária do sistema jurídico. Entretanto, após a vigência da Emenda Constitucional 45/2004, com a edição das súmulas vinculantes, como fonte do direito, observa-se uma valorização do costume jurisprudencial.

Desta feita, tivemos, também, um sistema próximo à Common Law, no qual os precedentes jurisprudenciais constituem a principal fonte do direito. Portanto, é evidente um sistema jurídico nacional "híbrido", onde surgem, por parte de muitos operadores do direito um equívoco na devida aplicação das normas, princípios e precedentes.

Considerando essa mistura de sistemas, não seria correto afirmar que o campo jurídico brasileiro deve ficar imune à influência daquilo que foi vivenciado pelas tradições que compõem o Direito ocidental. Entretanto, é certo que não podemos ficar imunes a elas perdidos em meio à tentativa de "fundar" um démodé Direito "efetivamente nacional" -, também é certo que precisamos passar em revista crítica daquilo que incorporamos dessas experiências, ao menos por questões de precisão científica (STRECK, 2017, p. 31).

Portanto, temos uma mistura de sistemas jurídicos, onde em casos de lacunas na norma, há vários mecanismos jurídicos para impor o direito, a justiça, não podendo sobrepor uma decisão subjetivista, sob a discricionariedade de quem aplica, desconhecendo até o mesmo os limites e princípios democráticos, pois passa um Poder adentrar na esfera constitucional do Poder legiferante.

Rev. de Argumentação e Hermenêutica Jurídica | e-ISSN: 2526-0103| Goiânia| v. 5 | n. 1 | p. 1 - 16 | Jan/Jun. 2019 


\section{CONTRIBUIÇÃO HERMENÊUTICA NO PENSAMENTO JURÍDICO HISTÓRICO E CONTEMPORÂNEO}

Conforme a moderna compreensão do sentido direito, considera-se a interpretação como uma das tarefas (atividade) mais importantes do jurista, isto é, a interpretação de textos jurídicos explicativos (doutrinários) e prescritivos (normas) que se desenvolve levando em conta determinadas situações a eles referidas.

Existe uma grande diferença entre o campo de ação da interpretação e da hermenêutica. A interpretação é um processo pelo qual se obtém o fim (determinação do sentido e alcance da norma). A hermenêutica é a teoria que serve de ferramenta para alcançar esse fim, pois os critérios hermenêuticos nos orientam na interpretação restritiva ou extensiva da norma. Dessume que: interpretação é o processo pelo qual se determina o sentido e alcance da norma, ao ser identificada com uma relação jurídica, enquanto a hermenêutica parte da ciência jurídica que tem por objeto o estudo e a sistematização dos processos interpretativos, tendo como finalidade a aplicação das regras da hermenêutica para o bom entendimento dos textos legais (SERRANO, 2015, p. 17-18).

A norma jurídica, em tese, deve trazer um conteúdo claro, não sendo necessário qualquer trabalho do seu aplicador para entender o seu sentido e o seu alcance. Entretanto, muitas vezes surgem no texto da lei ambiguidades, imperfeições ou falta de técnica, devendo haver a intervenção do intérprete, para pesquisar o verdadeiro sentido que o legislador realmente quis estatuir, bem como a eficácia social da norma jurídica.

Em casos tais entra em cena a interpretação da norma jurídica, buscando a mens legis, a intenção da lei; nascendo daí a hermenêutica, a ciência da interpretação, a teoria da arte de interpretar, de descobrir o sentido e o alcance da norma jurídica (TARTUCE, 2017, p. 26).

Ressalte-se que a expressão exegese também é utilizada como sinônima de hermenêutica. Entretanto, não se pode confundir exegese, que é utilizada com sentido de interpretação, com a Escola da Exegese.

Essa escola surgiu na França por volta do século XIX, conforme relata Zeno Veloso, diante de um verdadeiro fascínio em relação ao Código Civil de 1804. Ensina o mestre paraense que "para esta Escola, o legislador detinha o monopólio da revelação do direito (juspositivismo); o direito é a lei escrita. A vontade do legislador é que importa, não cabendo ao intérprete buscar a solução do caso em outras fontes, fora do texto legal, privilegiando-se, assim, a análise gramatical" (VELOSO, 2005, p. 66). Nem é preciso explicar por que essa escola encontra-se totalmente superada.

Pois bem, conforme salienta Maria Helena Diniz, desde os primórdios do estudo da interpretação da norma jurídica, duas grandes escolas surgem a respeito do critério metodológico que o aplicador deve seguir para buscar o sentido da norma (DINIZ, 2003, p. 420), a saber: Teoria subjetiva de interpretação - tese pela qual a meta da interpretação é estudar a vontade histórica do legislador. Teoria objetiva de interpretação - o intérprete deve se ater à real vontade da lei, à mens legis, desligando-se do seu elaborador.

Apesar da ciência de que predomina a adesão doutrinária à segunda tese, há doutrina compreendendo que não poderá prevalecer qualquer uma das teorias, devendo o aplicador do direito buscar elementos dos dois campos doutrinários, visualizando a norma sempre de forma plena (TARTUCE, 2017, p. 26).

Por isso, justifica-se a afirmação de Karl Engisch de que o aplicador do direito deve ser um jurista completo (ENGISCH, 1964).

De qualquer forma, antes de se pesquisar o sentido da norma jurídica é necessário saber o que se busca através dos signos que a exteriorizam e o que se estima como sua

Rev. de Argumentação e Hermenêutica Jurídica | e-ISSN: 2526-0103| Goiânia| v. 5 | n. 1 | p. 1 - 16 | Jan/Jun. 2019 
essência. Toda vez que nas leis se estabelecem comandos, o intérprete deve cultivar a habilidade para poder distinguir o sentido e alcance das normas nelas contidas, determinando qual a verdadeira necessidade que guiou o legislador a ditar esses comandos. Trata-se, pois, de verificar quais foram os propósitos do legislador e qual foi o espírito que presidiu a redação dos instrumentos jurídicos (SERRANO, 2015, p. 10).

\subsection{A interpretação normativa}

Não há de se negar que, concordando com Eugenio Bulygin, as normas jurídicas que integram o Direito de um país constituem um conjunto unitário ao que cabe atribuir o caráter de sistema, confundem-se, assim, os conceitos "ordem" e "sistema", pensando-se a ordem (o ordenamento) como um sistema de normas.

Nesse sentido, as técnicas de interpretação normativa nos remetem às formas ou tipos de interpretação que de fato, devem ser levadas em conta, na busca pelo sentido do texto legal. Decerto, pode haver a interpretação autêntica, realizada pelo próprio legislador. Pode a interpretação ser, ainda, doutrinária, quando feita pelos estudiosos do Direito, como no caso das obras jurídicas, dos manuais, das dissertações de mestrado e das teses de doutorado. Já, a interpretação judicial é realizada pelos órgãos do Poder Judiciário, que inclusive elabora súmulas aplicáveis a um determinado assunto.

No que concerne aos meios, a interpretação da norma pode ser classificada da seguinte forma, conforme se retira dos estudos fundamentais sobre a Teoria Geral do Direito:

1 Interpretação gramatical, aquela que consiste na busca do real sentido do texto legal a partir das regras de linguística do vernáculo nacional.

2 Interpretação lógica, que consiste na utilização de mecanismos da lógica, como de silogismos, deduções, presunções e de relações entre textos legais.

3 Interpretação ontológica, por meio da qual se busca pela essência da lei, a sua motivação a sua razão de ser (ratio legis).

4 Interpretação histórica, que consiste no estudo das circunstâncias fáticas que envolviam a elaboração da norma, procurando nesse contexto o real sentido do texto legal.

5 Interpretação sistemática, meio de interpretação dos mais importantes; visa sempre a uma comparação entre a lei atual, em vários de seus dispositivos e outros textos ou textos anteriores.

6 Interpretação teleológica, que objetiva a adequação da lei ao contexto da sociedade e aos fatos sociais.

Por fim, no que tange à extensão, é interessante deixar clara a seguinte classificação:

7 Interpretação declarativa, aquela desenvolvida nos exatos termos do que consta da lei, sem ampliar ou restringir o conteúdo do texto legal.

8 Interpretação extensiva, por meio da qual amplia-se o sentido do texto legal, sob o argumento de que o legislador disse menos do que pretendia, sendo interessante deixar claro que as normas que restringem a liberdade, caso da autonomia privada (liberdade contratual), e as normas de exceção, em regra, não admitem essa forma de interpretação.

9 Interpretação restritiva, pela qual restringe-se o texto legal, eis que o legislador disse mais do que pretendia.

Cumpre destacar a que todas essas espécies de interpretação não operam isoladamente, mas se completam. O renomado doutrinador alemão Karl Engisch, diante da ideia de jurista completo, recomenda que o cientista do direito, na hermenêutica, utilize todos os métodos interpretativos (ENGISCH, 1964).

\section{DAS REGRAS DE INTERPRETAÇÃO OU HERMENÊUTICA}

Conforme a perspectiva hermenêutica, considera-se o Direito como uma ciência

Rev. de Argumentação e Hermenêutica Jurídica | e-ISSN: 2526-0103| Goiânia | v. 5 | n. 1 | p. 1 - 16 | Jan/Jun. 2019 
interpretativa da norma, concepção essa que data do século XIX, mas que como atividade preponderante, ainda que incipiente, já tinha sido iniciada pelos chamados glosadores, principalmente, no século XI, época em que nasceria a chamada Ciência europeia do Direito (de Bolonha), quando apareceria uma resenha crítica dos Digestos justinianeus transformados em texto escolar do jus civile europeu. Os juristas da época tomaram como base os textos de Justiniano e passaram a dar-lhe um tratamento metódico, cujas raízes estavam nas técnicas explicativas usadas em aulas. Desenvolveu-se, assim, uma técnica especial de abordagem de textos pré-fabricados e aceitos por sua autoridade, caracterizada pela glosa gramatical e filológica, pela exegese ou explicação do sentido, pela concordância, pela distinção. Na leitura e aplicação dos textos dogmáticos, o jurista se empenhava numa harmonização, procurando paralelos e concordância entre eles, buscando também distinguir peculiaridades das regras, sanando, assim, as contradições. Essa tarefa pode ser denominada exegética ou interpretativa, era o modo de enfrentar a falta de acordo relativamente comum dos textos (FERRAZ, 1980, p. 21-22).

As legais há previsão no próprio texto normativo Ex. arts. $4^{\circ}$ e $5^{\circ}$ da Lei de Introdução às Normas do Direito Brasileiro, Decreto Lei $\mathrm{n}^{\circ} 4.657 / 42$, com as alterações introduzidas pela Lei $\mathrm{n}^{\circ} 12.376 / 2010$.

Já as regras científicas são propostas pela doutrina. Exemplo: Na obra clássica de Carlos de Carvalho, Nova Consolidação das Leis Civis cita: Art. 62: a ementa da lei facilita sua inteligência. $\S 1^{\circ}$ - No texto da lei se entende não haver frase ou palavra inútil, supérflua ou sem efeito. (FRANÇA, 2012, p. 36)

As regras de jurisprudência foram coligidas, em sua maioria, na lição de Washington de Barros Monteiro, exemplo:

\footnotetext{
$1 \mathrm{Na}$ interpretação deve-se sempre preferir a inteligência que faz sentido à que não faz. 2 Deve-se preferir a inteligência que melhor atenda à tradição do direito. 3 Deve ser afastada a exegese que conduz ao vago, ao inexplicável, ao contraditório e ao absurdo. (FRANÇA, 2012, p. 38)
}

O conjunto de regras da interpretação é, em suma, o que se denomina de hermenêutica (FRANÇA, 2012, p.32). A hermenêutica jurídica é composta por regras de interpretação, destacando as legais, as científicas e as de jurisprudência.

\section{INTERPRETAÇÃO E INTEGRAÇÃO DO DIREITO}

No Direito moderno, a interpretação (o domínio da sua hermenêutica) torna-se cada vez mais importante, e fica também evidente a necessidade de uma formação profissional que desenvolva as habilidades primárias do exegeta, que prime a compreensão de textos jurídicos. Ao observar essa necessidade, a Teoria do Direito privilegia os problemas basilares da interpretação, a saber, “o quê?”, "por quê?”, "para que?", “quando?" e "como?” interpretar, tais são as questões que o ensino jurídico há de prestigiar.

A perspectiva (sentido) hermenêutica aponta para uma necessidade intelectual própria do conhecimento e da resolução de problemas que derivam da dupla relação do homem com a natureza e do homem com a sua história. Assim sendo, a interpretação é de extrema importância para o acesso ao conhecimento, à argumentação e à pesquisa jurídica. Por esse motivo, a interpretação jurídica se torna necessária ao trabalho teórico e prático por expressar o Direito num conjunto de teorias, discursos, prescrições e práticas.

Pois bem, acerca do assunto que ora nos ocupa, observamos uma dada associação entre a interpretação e a compreensão. Na opinião de Ricoeur (1976, p. 85), por aproximar e tornar contemporâneo e semelhante o que se significa, isto é, por tornar próprio o que em

Rev. de Argumentação e Hermenêutica Jurídica | e-ISSN: 2526-0103| Goiânia | v. 5 | n. 1 | p. 1 - 16 | Jan/Jun. 2019 
princípio era estranho. É, pois, a interpretação de um conceito que identifica todo o processo que abarca a "explicação" e a "compreensão". A primeira, que visa à estrutura analítica do texto, e a segunda, que se dirige mais para a unidade intencional do discurso.

Nesse passo, a interpretação parece ser um ato necessário desenvolvido com o intuito de descortinar o significado das palavras dentro das proposições e as proposições dentro de um contexto. Portanto, compreender o sentido do locutor e da enunciação constitui um processo único e circular, sendo a relação entre o conceito de interpretação e o de compreensão, a que nos permite a comunicação dos problemas técnicos da exegese textual aos problemas mais gerais da significação e da linguagem (RICOEUR, 1978, p. 8). Faz-se necessária a interpretação porque nossa relação com o mundo se torna indireta, isto é, mediada por certas construções linguísticas.

Um dos problemas a ser enfrentado no contexto da hermenêutica jurídica contemporânea é que devemos acabar de definir o objeto sobre o qual recaem nossas interpretações. Deve-se, pois, refletir a respeito desse importante aspecto pensando que, além do normativo, existe outro contexto (o doutrinário) que também merece ser compreendido. Admitamos, pois, que como intérprete, nos envolvemos na procura tanto do sentido das normas quanto das diversas sentenças lidas nas fontes bibliográficas: livro, teses, artigos e demais documentos científicos.

De acordo com esse entendimento, ao falarmos especificamente da interpretação jurídica não só nos referiremos à interpretação da lei, mas também à interpretação de outros contextos, daí a ideia de que os processos interpretativos recaem sobre todo tipo de proposições, quer doutrinária quer normativa.

Podemos concluir que no processo de interpretação jurídica normativa temos como objeto imediato a lei e mais especificamente a norma e como objeto mediato o direito derivado: reconhecimento, faculdade, obrigação derivada da relação entre norma e fato. Já a interpretação que recai sobre teorias ou doutrinas aborda o texto (objeto imediato) para derivar de um significado (sentido) que, de acordo com Ricoeur (1976, p. 102), não se refere à ideia que alguém tem na sua mente, pois não é um conteúdo psíquico, mas um objeto ideal que pode ser identificado e reidentificado por diferentes indivíduos em tempos diferentes como um só e que tem um valor e oportunidade. Isso é conseguido com o auxílio da hermenêutica que como teoria nos fornece as regras interpretativas, ficando de lado a vontade, as emoções e crenças. Portanto,

Justifica a interpretação jurídica o fato de nem sempre existir um claro deslinde entre o acontecimento social e o texto jurídico. Aqui o operador do Direito enfrenta o problema da escolha correta, entre várias, da norma aplicável; pois, como se sabe o ordenamento jurídico se constitui como um conjunto de normas ordenadas e sistematizadas, de acordo com critérios diversos.

Outra das causas da interpretação jurídica pode consistir no fato de as leis positivas serem formuladas em termos gerais. O legislador fixa regras, consolida princípios, estabelece procedimentos, em linguagem clara e precisa, porém, ampla, sem descer a minúcias. Daí a necessidade de pesquisar a relação existente entre o texto abstrato e o caso concreto, isto é, entre a norma jurídica e o fato social.

Para tanto, é mister desenvolver um trabalho preliminar que consiste em procurar entender o sentido verdadeiro da regra positiva e, concomitantemente, seu respectivo alcance e extensão. Nesta perspectiva a interpretação será sempre necessária, pois o legislador estabelece regras gerais e não prescrições particulares, ou melhor, preceitos comuns a todos os cidadãos. Sendo certo que "a norma é geral, porque seu preceito se dirige

Rev. de Argumentação e Hermenêutica Jurídica | e-ISSN: 2526-0103| Goiânia | v. 5 | n. 1 | p. 1 - 16 | Jan/Jun. 2019 
indiscriminadamente a todos. Especificando melhor, a todos, segundo a igualdade de situações. A todos os brasileiros natos, a todos os empregados públicos, a todos os engenheiros agrônomos e assim por diante. Forma-se uma progressão do mais geral (brasileiros) ao menos geral ou especial (engenheiros agrônomos com curso de pósgraduação)". (RICOEUR, 1976, p. 179)

Damos como certo que os problemas da interpretação das normas também estão vinculados à linguagem e à lógica jurídica e por este motivo ao interpretar se devem utilizar métodos que permitam a verificação da intenção do texto jurídico, através da análise do sentido das palavras utilizadas. O conhecimento do uso da linguagem e da lógica jurídica nos ajuda a compreender o sentido dado à redação do texto. Igualmente, o conhecimento do uso da linguagem e da lógica jurídica é ferramenta fundamental que nos permite argumentar uma sentença, fundamentar adequadamente um relatório e realizar todo o trabalho de aplicação da lei.

É possível, com efeito, que uma palavra isolada não adquira um significado próprio; pois, nem sempre uma palavra é suficiente para representar uma ideia. Tampouco a combinação de duas ou mais palavras (frase) é condição para significar alguma coisa.

O que tenho a dizer é que frases sem sentido não expressam nada, portanto não merecem interpretação. Além disso, determinadas frases com sentido podem resultar ser certas ou oportunas para alguns, porém não aceitas (não válidas) por uma parte da comunidade.

Daí que toda interpretação recaia sobre frases às quais normalmente atribuímos um ou vários sentidos. Eu digo: proposições, ou seja, construções linguísticas por meio das quais, de forma lógica e coerente, procuramos descrever, explicar, relacionar ou prescrever alguma coisa (objetos, fenômenos, ideias e condutas). É o conteúdo de um enunciado. Pouco nos importa saber se esse conteúdo não existe enquanto entidade abstrata (como dizem os nominalistas), ou se é um construto mental (como dizem os conceitualistas), ou se, finalmente, existe num mundo ideal (como dizem os platônicos).

De fato, são as proposições as que nem sempre compreendemos uniformemente. É a sua aparente correspondência com um mundo que parece exigir do leitor uma interpretação. Assim sendo, sob a noção de unidade da linguagem humana os processos interpretativos se desenvolvem respeitando uma visão de "estrutura", "ordem" ou "sistema". Justifica-se, assim, a tese de que a ciência jurídica, na sua perspectiva hermenêutica, pode ser vista como sendo constitutiva de um conjunto de atividades interpretativas que visam compreender o comportamento humano. Daí que qualquer teoria sobre a interpretação do Direito procure explicar, além da unidade da linguagem jurídica, um sentido, isto é, a compreensão do porquê das proposições jurídicas, seguindo a sistemática das mesmas dentro de um contexto.

No processo de análise e compreensão da realidade e dos textos está implícito um tipo específico de unilateralidade que fundamenta o caráter conjetural da interpretação e que limita a credibilidade dos métodos interpretativos. Eis que, como bem acentua Ricoeur, "a exegese já nos habituou com a ideia de que um texto tem vários sentidos, de que tais sentidos se imbricam um no outro, de que o sentido espiritual é 'transferido' do sentido histórico ou literal por acréscimo de sentido deste" (RICOEUR, 1978, p. 14).

Certamente, a metodologia para a interpretação de textos normativos, ainda, está por ser construída. Contudo, é a inexistência de métodos para conjeturas a que torna legítima a procura por técnicas e regras que nos permitam o teste e a crítica científica. Assim sendo, nada impede o exercício da crítica quando procuramos oferecer uma melhor compreensão dos textos. Eis o que estimula os estudos sobre as formas de desenvolver os processos interpretativos.

Rev. de Argumentação e Hermenêutica Jurídica | e-ISSN: 2526-0103| Goiânia | v. 5 | n. 1 | p. 1 - 16 | Jan/Jun. 2019 
A verdade é que cada forma de interpretar corresponde a um ou vários métodos interpretativos, muitas vezes diferentes e até opostos. Isso porque a um mesmo texto ainda podem ser atribuídos vários sentidos. Assim, por exemplo, na História, na Teologia, na Filosofia e no Direito encontramos formas diferentes de significar as mesmas questões e de abordar os mesmos textos.

Em efeito, "se um texto pode ter vários sentidos, por exemplo, um sentido histórico e um sentido espiritual, deve-se recorrer a uma noção de significação muito mais complexa que a dos signos ditos unívocos, exigida por uma lógica da argumentação. Enfim, o próprio trabalho da interpretação revela um desígnio profundo: o de superar uma distância, um afastamento cultural, o de equiparar o leitor a um texto que se tornou estranho e, assim, incorporar seu sentido à compreensão presente que um homem pode obter dele mesmo". (RICOEUR, 1978, p. 8)

Também pode acontecer que uma interpretação seja hoje mais aceitável do que foi ontem e, ainda, menos aceitável do que será amanhã. Isto porque o avanço das ciências, das técnicas e da tecnologia faz e fará possível a constatação e compreensão de certas relações antes não observadas ou compreendidas e a solução de novos problemas.

Além do citado, três objeções merecem destaque:

Primeira, é certo que por meio dos conceitos e proposições significamos os objetos e fenômenos; mas, também é certo que tais construções não são fotocópia exata da realidade observada, visto que nem sempre são capazes de representar, integralmente, todas e cada uma das qualidades ou características pertencentes a ditos objetos.

Segunda, nem sempre lidamos com conceitos concretos (ou com proposições sintéticas). Com frequência, lidamos com ideias abstratas, o que faz com que se duvide da objetividade (valor e certeza) do conhecimento, ou de qualquer tipo de referência que tenha como base tais conceitos abstratos, exemplo, beleza, bondade, justiça, democracia, equidade, verdade, etc.

Terceira, dentro de um dado contexto, as palavras podem parecer ser vagas ou ambíguas e as proposições contraditórias e inconsistentes. É o que chamam de palavras polissêmicas, isto é, palavras que têm mais de um significado.

Penso, por exemplo, que a anterior problemática constitui a razão das falsas crenças, de conflitos teóricos, de disputas e de guerras. São questões que nos fazem duvidar da objetividade do conhecimento humano em geral e de algumas teorias e conclusões científicas em particular.

Urge ao intérprete preocupar-se pela demonstração de seus resultados e não pela procura de verdades aparentes, objetivos geralmente vistos como inalcançáveis. É mister nos preocuparmos com a coerência de nossas proposições e teorias, procurando demonstrar que, para chegar a um resultado, fomos capazes de percorrer um caminho, usarmos uma lógica (metodologia) dentro de um processo que aqui chamamos de pesquisa.

No plano epistemológico, se diz não haver dois métodos, o método explicativo e o método compreensivo, sendo que somente a explicação é metódica. A compreensão é, antes, o momento não-metódico que nas ciências da interpretação se forma com o momento metódico da explicação. Este momento precede, acompanha, limita e também envolve a explicação. Em contrapartida, a explicação desenvolve, analiticamente, a compreensão (RICOEUR, [s.d.] p. 182). A conclusão é que tais divergências também estão presentes no Direito, questão esta que estimula, por parte dos juristas, o estudo das regras da hermenêutica.

Do ponto de vista jurídico, a hermenêutica (hermenêutica jurídica) objetiva o estudo e a sistematização dos processos aplicáveis para determinar o sentido e o alcance das

Rev. de Argumentação e Hermenêutica Jurídica | e-ISSN: 2526-0103| Goiânia | v. 5 | n. 1 | p. 1 - 16 | Jan/Jun. 2019 
expressões do Direito (MAXIMILIANO, 1996, p. 1). É nesse sentido que a hermenêutica jurídica funciona como uma parte da ciência do Direito que auxilia os processos interpretativos. Vale aqui observar uma importante distinção entre o campo de ação da interpretação e da hermenêutica. Se interpretação é um processo pelo qual se pretende alcançar um fim (determinação do sentido e alcance da norma), a hermenêutica é a teoria que serve de ferramenta para alcançar esse fim, pois os critérios hermenêuticos orientam a interpretação jurídica.

\subsection{Métodos e técnicas de integração}

O estudo dos métodos e das técnicas de interpretação e de integração normativa é extremamente relevante para todo estudioso do Direito. Tem-se dito que tal estudo deriva do interesse público, que exige que as leis tenham aplicação fiel ao pensamento do legislador. É de interesse público a interpretação das leis, porque nenhuma lei se faz a não ser para utilidade pública. Então, se é o interesse público que faz a lei, é necessário que ela tenha uma execução uniforme e não a pode ter sem que haja regras comuns que sujeitem o espírito dos que se acham encarregados de executá-la. (PAULA, 1984, p. 3)

Fale-se assim de técnicas interpretativas como sendo procedimentos interpretativos que se seguem com a finalidade de captar o sentido e alcance da proposição jurídica dentro de um determinado contexto, isto é, doutrinário ou normativo. A respeito dessas técnicas, aceitaria Luis Diez-Picazo (1995, p. 117), que o ponto de partida de toda interpretação é a letra (o sentido próprio das palavras) da proposição normativa, pois durante a interpretação gramatical cabe a aplicação das regras da semântica, que tratam de fixar o sentido ou os possíveis sentidos que possui cada uma das palavras do texto. De acordo com o citado autor, outro elemento a ser considerado é o contexto, pois o intérprete relaciona ou vincula o sentido das palavras ao contexto, constituindo-se este em outro momento da interpretação gramatical, que aqui seria sintática. Conclui-se, pois, que a interpretação sintática não tem como objetivo a fixação do sentido de uma palavra, mas a fixação do sentido de uma proposição completa, através da coordenação gramatical que dentro dela têm as diferentes palavras e seu respectivo valor. Desta forma, o contexto é um termo com o que se alude à tradicional interpretação sistemática.

A interpretação segundo o contexto normativo aconselha estabelecer conexão entre todos os preceitos legislativos que tratam de uma determinada questão, por pressupor que entre eles existe uma coerência e uma interdependência. Nesse tipo de análise e pesquisa, os antecedentes históricos e legislativos (interpretação histórico-evolutiva) também são importantes, cuja invocação tem por objetivo conhecer a problemática para a qual a norma trata de dar uma solução ou, dito em outros termos, conhecer os critérios diretivos para a resolução das questões às quais se deve o surgimento da norma. Não se trata de uma reconstrução da vontade do legislador, mas de um meio para o melhor entendimento daquilo que ele ordenou (chama-se de história remota e hodierna da instituição, plasmada em anteprojetos, projetos de leis, etc.).

Desse modo, têm igual importância a determinação do espírito e a finalidade das proposições e de sua referência empírico-sociológica, isto é, a observação do contexto e do tempo em que se há de aplicar as normas. A observação de tal elemento permite avaliar a série de fatores ideológicos, morais e econômicos, que revelam e plasmam as necessidades e o espírito da comunidade em cada momento histórico. O elemento sociológico obriga a um ajuste da interpretação dos preceitos, mas não a uma modificação ou não-aplicação dos mesmos.

O Direito comumente se nos apresenta como sendo o resultado de uma construção de teorias e modelos jurídicos ligados ora a uma tradição que se corresponde com uma visão

Rev. de Argumentação e Hermenêutica Jurídica | e-ISSN: 2526-0103| Goiânia| v. 5 | n. 1 | p. 1 - 16 | Jan/Jun. 2019 
temporal e espacial, sendo também finalidade da ciência jurídica propor um conjunto de técnicas e procedimentos para a melhor compreensão e resolução dos problemas jurídicos.

Assim, admitindo-se que a interpretação jurídica é uma das atividades centrais do Direito, considera-se que este (o Direito) é essencialmente uma ciência hermenêutica, onde o intérprete busca o sentido, alcance e finalidade dos textos legais. Por causa desse entendimento, a hermenêutica parece haver orientado o pensamento de uma grande parte dos juristas, para quem interpretar seria atribuir um sentido à norma jurídica, observando a vontade do legislador original (primitivo) e a realidade ou fenômeno vinculado a ela, consistindo a atividade interpretativa na busca do sentido e do significado das normas jurídicas, através dos textos ou signos de exteriorização.

É, no entanto, comum encontrar nas obras de destacados hermeneutas uma concepção que explica a interpretação jurídica como sendo um processo importante por meio do qual o intérprete, com o auxílio da hermenêutica jurídica, se situa no lugar e nível do legislador para repetir artificialmente sua atividade. Admitem-se duas teorias jurídico-interpretativas.

1 A teoria subjetiva (vontade psicológica do legislador).

2 A teoria objetivista (vontade normativa da lei).

Por meio dessas teorias confrontam-se dois possíveis objetos do processo de interpretação jurídica: a vontade do legislador versus o texto legal. Quanto a este ponto, considera-se o seguinte.

O criador da lei, assim como afirmam Luis Diez-Picazo e Antonio Gullón (1995, p. 114-115), desempenha um papel importante, pois sua vontade se converte em texto legal. As representações mentais, as expectativas e os propósitos do legislador, que não alcançaram expressão na lei, carecem de obrigatoriedade. Só as manifestações da vontade vertidas nas normas têm valor e por isso apenas é válida a vontade que resulta do texto legal. Assim, concluem os citados autores, a interpretação objetiva constitui o sistema mais importante para completar e facilitar o progresso do ordenamento jurídico. Mas, segundo penso, uma interpretação objetiva da norma jurídica é capaz de fazer frente aos fenômenos e situações que o legislador histórico não conhecia e não tinha motivo para conhecer. Desta feita, o intérprete deve adaptar o ordenamento jurídico que está em renovação, pois dentro dele cada nova disposição irradia uma força sobre as anteriores e sobre todo seu conjunto.

Entretanto, o jurista hodierno parece enfrentar um aparente conflito teórico que, segundo Tércio Sampaio (1980, p. 72), ainda não tem sido devidamente resolvido, porém que poderia ser dissipado se considerarmos que o ato da interpretação tem por objeto não um texto, mas o sentido que ele expressa que foi determinado ou é determinado por outro ato interpretativo - ou da autoridade competente -, que por sua vez é condicionado por uma série de fatores que podem alterá-lo, restringi-lo ou aumentá-lo. Assim, continua o citado autor, interpretar é compreender outra interpretação (a fixada na norma), existindo nesse sentido dois atos, um que dá à norma o seu sentido e outro que tenta captá-lo. Portanto, para que possa haver interpretação jurídica é preciso que ao menos um ato doador de sentido seja fixado.

Mas, a discussão sobre os limites da interpretação extensiva e da analogia trouxe um aspecto importante para a compreensão da hermenêutica. Trata-se de um problema típico da teoria dogmática da interpretação que se refere à possibilidade de, por via da hermenêutica, suprirem-se as lacunas do ordenamento (FERRAZ JUNIOR, 2018, p.262).

Segundo Tercio Sampaio Ferraz Junior (2018, p.263) a questão dos modos de integração diz respeito aos instrumentos técnicos à disposição do intérprete para efetuar o preenchimento ou a colmatação da lacuna, não servindo apenas como preenchimento como

Rev. de Argumentação e Hermenêutica Jurídica | e-ISSN: 2526-0103| Goiânia| v. 5 | n. 1 | p. 1 - 16 | Jan/Jun. 2019 
também para a constatação da lacuna. Portanto os referidos instrumentos técnicos possuem dupla utilidade.

Aqui podemos, novamente, utilizar a doutrina do professor referenciado, o qual destaca que "embora ciente da precariedade de qualquer classificação, vamos distinguir entre instrumentos quase-lógicos (quase porque não obedecem estritamente ao rigor da lógica formal) e instrumentos institucionais (manifestam argumentos materiais)". (FERRAZ JUNIOR, 2018, p. 264)

Instrumentos quase-lógicos: analogia, indução amplificadora e interpretação extensiva. Instrumentos institucionais: costumes, princípios gerais de direito e equidade.

Há que se destacar os limites à integração, pois os meios de integração estão submetidos a controles. É o problema dos limites à integração. Um dos controles é que nenhum meio integrador gera, por si só, um efeito generalizante. O preenchimento da lacuna é sempre para o caso concreto. (FERRAZ JUNIOR, 2018, p.268)

Contudo, a questão da lacuna e dos limites à integração é uma espécie de invenção do pensamento dogmático que permite, de modo controlado, a decidibilidade de conflitos não regulados de forma positiva.

Funciona como uma regra permissiva, doutrinária, que autoriza o intérprete a se valer dos meios de integração nos limites que à própria doutrina parece reconhecer, mas na verdade estabelece: em caso de lacuna pode o intérprete... Ou seja, embora o conceito designe falta, ele oculta a superabundância de normas, assegurando-se, destarte um dos princípios caracterizadores do legislador racional: a omnicompreensividade. (2018, p. 270)

\section{DA FUNÇÃO SOCIAL DA HERMENÊUTICA}

A hermenêutica jurídica é uma forma de pensar dogmaticamente o direito que permite um controle de possíveis incidências sobre a realidade antes que elas ocorram, A hermenêutica possibilita neutralizar os conflitos sociais, ao projetá-los numa dimensão harmoniosa. Ela não elimina as contradições as tornas suportáveis.

Na perspectiva da dimensão objetiva (vontade da lei e não do legislador) impõe-se a função instrumental integradora e hermenêutica do princípio da dignidade da pessoa humana, na medida em que serve como parâmetro para aplicação, interpretação e integração não apenas dos direitos e das demais normas constitucionais, mas de todo o ordenamento jurídico. (SARLET, 2015, p. 103)

Cada vez mais os Tribunais utilizam o princípio da dignidade da pessoa humana como critério hermenêutico, no sentido de interpretação conforme a dignidade e os direitos fundamentais. ${ }^{1}$

\section{DA DISCRICIONARIEDADE NAS DECISÕES JUDICIAIS}

Após uma visão, sucinta, da hermenêutica e interpretação das normas, passa ao ponto nodal no presente trabalho.

Hodiernamente nos deparamos com casos jurídicos, onde o intérprete afasta o teor da lei, democraticamente legítima, sob o fundamento de uma eventual superação da literalidade do texto legal, seja nos denominados "casos fáceis" ou nos "casos difíceis".

Não se pode olvidar, conforme Lenio Streck, que a literalidade e ambiguidade são conceitos intercambiáveis que não são esclarecidos numa dimensão simplesmente abstrata de

\footnotetext{
${ }^{1}$ Exemplos: ADPF 132 - O STF com fulcro na dignidade da pessoa humana esposou interpretação constitucional conforme assegurando a equiparação entre as uniões estáveis de companheiros heterossexuais e as uniões de pessoas do mesmo sexo. (ADPF 132, Rel. Min. Carlos Britto, 05.05.2011); ADPF 54 - O STF interpretou extensivamente, com base no princípio da dignidade da pessoa humana, as hipóteses para afastar a ilicitude da prática do aborto nos casos de anencefalia fetal. (ADPF 54, Rel. Min. Marco Aurélio, julgada em 11 e 12.04.2012)
}

Rev. de Argumentação e Hermenêutica Jurídica | e-ISSN: 2526-0103| Goiânia| v. 5 | n. 1 | p. 1 - 16 | Jan/Jun. 2019 
análise dos signos que compõem um enunciado. Tais questões sempre remetem a um plano de profundidade que carrega consigo a "dobra da linguagem", vale dizer, o contexto no qual a enunciação tem sua origem. Esse é o problema hermenêutico que deve ser enfrentado. Problema esse que argumentos despistadores, como o da "superação" da literalidade da lei, só fazem esconder e, o que é mais grave, com riscos de macular o pacto democrático. (2017, p. 44)

A doutrina da Critica Hermenêutica do Direito tem buscado enfrentar esses problemas, sendo o mentor intelectual o Professor Lenio Streck.

De forma sucinta recorda-se que antes da formação do Estado Moderno, de fato, o juiz ao resolver as controvérsias não estava vinculado a escolher normas emanadas do legislativo, tinha uma liberdade de escolha na determinação da norma a aplicar, podendo utilizar os costumes, critérios de equidade, regras elaboradas por juristas, ou ainda, princípios da razão natural. (Bobbio, 2006)

Entretanto, com o surgimento do Estado Moderno o juiz é transformado em órgão do Estado, deixando de ser um livre órgão da sociedade. $\mathrm{Na}$ análise histórica, tal fato é responsável na transformação do juiz em titular de um dos poderes estatais, o judiciário, subordinado ao legislativo. Daí impõe-se ao juízo que a resolução das controvérsias seja submissa às regras emanadas pelo poder legislativo. (Bobbio, 2006)

Não há possibilidade acadêmica no presente trabalho para desenvolver a parte histórica quanto ao jusnaturalismo até perpassar ao juspositivismo. Assim já salientamos que o positivismo jurídico como paradigma teórico não é reconhecido de forma unânime, ao contrário.

Considerando o sistema jurídico no Brasil, simbiose de sistemas da civil law e da common law, devemos citar, como exemplo, os trabalhos de Hart no direito anglo saxão e de Bobbio na tradição continental. Os referidos autores são citados apenas como um dos expoentes nos sistemas diversos prefalados, porém há diversos escritores que se dedicaram ao assunto, cada qual em sua visão acadêmica, seja no campo da teoria, da metodologia ou da ideologia.

Essa distinção deve ser sempre analisada pelo operador do direito, pois não é prudente importar teorias desprovidas da análise de sua origem. Ou seja, é muito comum embasar determinados temas em institutos trazidos do sistema anglo saxão, contudo, ao aplicar em nosso ordenamento, não se considera há existência do direito positivado. Melhor dizendo, como sustentar a aplicação teórica de um instituto com base no direito consuetudinário, quando em nosso sistema há o direito descrito pelo legislador.

Essa é uma das questões que tem andado em nosso direito. Se há uma norma positivada, não se pode utilizar de métodos do direito consuetudinário, o qual não prevê a referida norma descrita, aquela que após a identificação empírica o poder constitucionalmente constituído legislou, de forma geral, para ordenar os problemas na sociedade.

A discricionariedade na decisão surge quando o juiz, diante de um caso específico, não tem uma regra de direito clara. Daí exsurge o que no positivismo jurídico é denominado a teoria dos "casos difíceis", onde o juiz tem o poder discricionário para decidir o caso.

A teoria dos casos difíceis descreve que cabe ao juiz aplicar o direito criado por outras instituições; não devem criar um novo direito. Isso é o ideal, mas por diversas razões não pode ser plenamente concretizado na prática. As leis e as regras do direito costumeiro (common law) são quase sempre vagas e devem ser interpretadas antes de se poder aplica-las aos novos casos. (DWORKIN, 2017, p. 128)

Rev. de Argumentação e Hermenêutica Jurídica | e-ISSN: 2526-0103| Goiânia | v. 5 | n. 1 | p. 1 - 16 | Jan/Jun. 2019 
Mais uma vez veja a importância da distinção quanto a origem da teoria citada e o respectivo sistema. Visto que cada qual possui uma especificidade.

Entretanto comumente depara-se com julgados onde o julgador, mesmo diante de uma regra clara, busca-se uma interpretação da norma, porém contrária ao próprio sentido linguístico.

Neste sentido é importante lembrar a lição que o texto constitucional traz uma necessária vinculação constitucional, o que Jon Elster denomina de pré-compromisso constitucional. Quando se acredita poder passar por cima do Direito constitucional escrito, podem tais decisões ser tidas como mais apropriadas que as de uma interpretação mais fiel à lei, liberando-se o caminho para se ludibriar a Constituição, em prol de interesses discricionários controvertidos? (STRECK, 2017, p. 84)

Desta feita, abandona-se a ideia da Constituição escrita pelo estado de insegurança que isso gera. $O$ texto escrito tem uma clara necessidade de vinculação, que não pode ser superada, sob pena de causar fissuras na institucionalidade (HESSE, 1998).

O fato de existir uma norma expressa e clara para a concretude de um caso sob análise, não permite ao julgador suprimir a norma derivada de órgão constitucionalmente constituído para "legislar" através do Poder Judiciário.

Convém salientar que o decisionismo de Hans Kelsen não foi superado, bem como a discricionariedade de Hart vem sendo revista pela teoria da argumentação, com um viés diferente, sob uma racionalidade argumentativa.

Para lembrarmos a teoria da argumentação de Alexy não vem sendo devidamente utilizada no Brasil no que tange a discricionariedade das decisões, visto que "não há uma decisão judicial que tenha aplicado a esquematização constante na tese alexiana (STRECK, 2014, p. 413).

Neste sentido, recorda-se que Alexy na teoria da argumentação admite a tese da "textura aberta" do direito estabelecida por Hart na obra o Conceito de Direito, onde neste espaço seria o local necessário para os argumentos morais no direito. Alexy reconhece que há casos em que o discurso jurídico não dá conta, devido a textura aberta, os chamados hard cases (Hart). Nesses casos, a moral é empregada complementarmente para resolvê-los. Ou seja, o intérprete deve pautar-se a partir de diferentes razões que não propriamente aquela extraída do direito (STRECK, 2014, p. 415).

Considerando esta abertura pela moral continuamos tendo decisões subjetivas e, portanto, discricionárias, onde também foi avaliado por Gustav Radbruch a denominada fórmula Radbruch. Fórmula esta que entendeu que a extrema injustiça não é direito.

Contudo tal fórmula não teve grande repercussão, haja vista o alto teor de insegurança jurídica. A partir desta fórmula Alexy trabalhou a ideia com novos contornos, dispondo que não era em qualquer caso de grave injustiça se aplicaria a citada fórmula, entretanto apenas em extrema injustiça, onde haja o descumprimento do núcleo dos direitos fundamentais. Daí a teoria dos Direitos Fundamentais.

Assim Alexy descreve que "Os direitos fundamentais não são um objeto passível de ser dividido de uma forma tão refinada que inclua impasses estruturais - ou seja, impasses reais no sopesamento -, de forma a torná-los praticamente sem importância. Neste caso, então, existe uma discricionariedade para sopesar, uma discricionariedade tanto do legislativo quanto do judiciário." (ALEXY, 2008, p. 611)

\section{CONCLUSÃO}

Como resultado da pesquisa desenvolvida no presente estudo podemos concluir que é certo que nos dias atuais, quando se fala em Ciência do Direito, no sentido do estudo nas Faculdades de Direito, há uma tendência de identifica-lo com um tipo de produção técnica,

Rev. de Argumentação e Hermenêutica Jurídica | e-ISSN: 2526-0103| Goiânia | v. 5 | n. 1 | p. 1 - 16 | Jan/Jun. 2019 
destinada apenas a atender às necessidades do profissional, no desempenho imediato de suas funções. Sendo conduzido a uma especialização, fechada e formalista (especialização indesejável porque demasiado restritiva). Com isso o estudo paga um preço: o risco de distanciamento progressivo da própria realidade social.

Sem prejuízo do outro lado da moeda, onde surge o denominado "vício intelectual", um fenômeno sociocultural comum nas universidades brasileiras, definido como apatia, falta de atitude, filosofia do consumo, o costume ou fraqueza cultural, fenômeno que o discente não se interessa pela leitura, não participa e entende que o conhecimento e compreensão das lições são consequências por efetuar o pagamento das mensalidades. (SERRANO, 2017a, p. 14).

A interpretação e integração não se limitam a mera interpretação gramatical, deve buscar a finalidade do texto com fito dos valores sociais.

Encerramos com o aprendizado que através da hermenêutica filosófica, com os aportes da teoria integrativa de Dworkin (que redunda na crítica hermenêutica do direito), representa em um contexto pós-metafísico e pós positivista, uma blindagem contra interpretações deslegitimadoras e despistadoras do conteúdo que sustenta o domínio normativo dos textos constitucionais. Trata-se de substituir qualquer pretensão solipsista pelas condições históricoconcretas, a questão da tradição, da coerência e da integridade, para bem poder inserir a problemática na superação do esquema sujeito-objeto pela hermenêutica jurídico-filosófica. (STRECK, 2017, p. 651)

Dito de outra maneira trata-se de evitar ativismos (aqui no sentido quando se decide a partir de argumentos de política, enfim, quando substitui o Direito, por convicções pessoais de cada magistrado). Os argumentos devem ser de princípios e não de política, para sempre interpretar e aplicar o direito, fazendo justiça.

Há diferença entre a hermenêutica filósofica (Dworkin) e a teoria da argumentação jurídica (Alexy), visto que esta teoria estabelece os princípios como mandados de otimização, circunstância que traz à colação a subjetividade do intérprete, àquela parte da tese de que os princípios introduzem o mundo prático no direito, "fechando" a interpretação, isto é, diminuindo - ao invés de aumentar - o espaço da discricionariedade do intérprete; além disso, o círculo hermenêutico e a diferença ontológica colocam-se como blindagem contra relativismos. (STRECK, 2014, p. 418)

Pensar que a discricionariedade das decisões é algo inerente à aplicação do direito é reconhecer o protagonismo judicial. Ademais a discricionariedade não se correlaciona, neste sentido, com a democracia.

Por fim, até mesmo as teorias que servem como suposto fundamento para embasar as decisões judiciais, não são aplicadas em sua integralidade. O próprio Supremo Tribunal Federal faz constantes referências ao termo ponderação, mas é extremamente difícil dizer quando é que estamos diante de um acórdão em que realmente foram percorridas todas as fases do procedimento da ponderação. Há frequentes menções a princípios constitucionais em conflito, mas em regra, raramente encontra-se um voto no qual todas as fases da ponderação estabelecidas por Alexy - tenham sido ao menos sugeridas pelo Ministros. (STRECK, 2014, p. 420)

Assim verifica-se uma importação de teorias originárias de sistemas diversos sem respeitar até mesmo a intelectualidade do seu autor, colocando um grau exacerbado de subjetividade, consequentemente, discricionariedade sob o pretexto de aplicar a justiça, sobrepondo as normas positivadas no ordenamento, visto que, verifica-se a discricionariedade até mesmo em decisões denominada "fáceis". Portanto praticando um ativismo judicial,

Rev. de Argumentação e Hermenêutica Jurídica | e-ISSN: 2526-0103| Goiânia | v. 5 | n. 1 | p. 1 - 16 | Jan/Jun. 2019 
desrespeitando as normas e as próprias teorias utilizadas, surgindo, assim, uma insegurança jurídica.

A hermenêutica e a interpretação servem para subsidiar a solução dos casos difíceis, quando ocorrer lacuna na norma.

\section{REFERÊNCIAS}

ALEXY, Robert. Teoria dos Direito Fundamentais. Tradução Virgilio Afonso da Silva. São Paulo: Malheiros, 2008.

BULYGIN Eugenio. Notas sobre la Regla de Reconocimiento. In, Doxa. N 9 - Cuadernos de Filosofía del Derecho. Disponível em:

http://www.direitodoestado.com.br/bibliotecavirtual/497/ Acesso: 23,07,2014.

DIEZ-PICAZO, Luis; GULLÓN, Antonio. Instituciones de Derecho Civil. Vol. I. Editorial Tecnos, S. A., Madri, 1995.

. Experiencias jurídicas y teoría del derecho. 3. ed. Corregida y puesta al día. España, Barcelona: Ariel, 1999.

DINIZ, Maria Helena. Compêndio de introdução ao estudo do direito. 15. ed. São Paulo: Saraiva, 2003.

DWORKIN, Ronald. Levando os direitos a sério. 3. ed. São Paulo: WMF Martins Fontes, 2017.

ENGISCH, Karl. Introdução do pensamento jurídico. 2. ed. Lisboa: Fundação Calouste Gulbenkian, 1964.

FERRAZ JUNIOR, Tercio Sampaio. Introdução ao estudo do direito: técnica, decisão, dominação. 10 ed. São Paulo: Atlas, 2018.

A ciência do direito. 2. ed. São Paulo: Atlas, 1980. Introdução ao estudo do Direito. 2. ed. São Paulo: Atlas, 1994.

FRANÇA. R. Limongi. Hermenêutica Jurídica. 11. ed. São Paulo: Saraiva, 2012.

HESSE, Konrad. Elementos de direito constitucional da República Federativa da Alemanha. Porto Alegre: Fabris, 1998.

MAXIMILIANO, Carlos. Hermenêutica e Aplicação do Direito. 16. ed. Rio de Janeiro: Forense, 1996.

. Hermenêutica e Aplicação do Direito. 19. ed. Rio de Janeiro: Forense, 2003.

PAULA Baptista, Francisco de. Compêndio de Hermenêutica Jurídica. São Paulo: Saraiva, 1984.

RICOEUR, Paul. O Conflito das Interpretações: ensaios de hermenêutica. Trad. Hilton Japiasso. Rio de Janeiro: Imago, 1978.

Rev. de Argumentação e Hermenêutica Jurídica | e-ISSN: 2526-0103| Goiânia | v. 5 | n. 1 | p. 1 - 16 | Jan/Jun. 2019 
[s.d.]. $70,1976$.

. Do texto à Ação. Trad. Maria Jose Sarabando Alcino Cartaxo. Portugal: Rés,

SARLET, Ingo Wolfgang. Dignidade (da pessoa) Humana e Direitos Fundamentais na

Constituição Federal de 1988. 10 ed. Porto Alegre: Livraria do Advogado, 2015.

SERRANO, Pablo Jiménez. Hermenêutica e interpretação jurídica. [livro eletrônico] / Rio de Janeiro: Jurismestre, 2015.

Práticas da Argumentação Jurídica: técnicas do raciocínio e da persuasão

judicial. Rio de Janeiro: Jurismestre, 2017a.

Teoria do direito: contribuição ao pensamento jurídico contemporâneo. Rio de Janeiro: Jurismestre, 2017b.

STRECK, Lenio Luiz. Verdade e Consenso. 6. ed. São Paulo: Saraiva, 2017.

Hermenêutica jurídica e(m) crise: uma exploração hermenêutica da construção do Direito. 11 ed. Porto Alegre: Livraria do Advogado, 2014.

TARTUCE, Flávio. Direito civil, v. 1: Lei de Introdução e Parte Geral - 13. ed. rev., atual. e ampl. - Rio de Janeiro: Forense, 2017.

VELOSO, Zeno. Comentários à Lei de Introdução. Belém: Unama, 2005. 